\title{
Microscopic Autoradiography
}

National Cancer Institute

\section{Source}

National Cancer Institute. Microscopic Autoradiography. NCI Thesaurus. Code C18638.

Autoradiographic analysis performed by mounting the object for microscopy (e.g., on a

glass slide) and bathing the object with a photographic emulsion that will record

radioactive disinteg rations occurring at close proximity. 